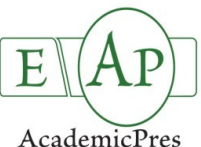

\title{
Morphological and Physiological Changes in Sedum spectabile during Flower Formation Induced by Photoperiod
}

\author{
Cuiqin $Y_{A N G}^{1,2,3}$, Xiyao WANG ${ }^{2}$, Yaoguo QIN ${ }^{4}$, Xin $S N^{2}$, Qiang WANG ${ }^{2}$, \\ Honghui LIN ${ }^{1 *}$, Dehui XI ${ }^{1}$ \\ ${ }^{I}$ Sichuan University, Key Laboratory of Bio-resources and Eco-environment (Ministry of Education), State Key Laboratory of Hydraulics and Mountain River Engineering, \\ CollegeofLifeScience, 610065Chengdu PRChina;hblin@scuedu.cn (*orrespondingauthor) \\ ${ }^{2}$ Sichuan Agricultural University, Collegeof Agronomy, 611130 Chengdu, PR China \\ ${ }^{3}$ Chinese Academy of Sciences, Chengdu Institute of Biology, 610041 Chengdus PR China \\ ${ }^{4}$ Sichuan Agricultural University, Collegeof Horticulture, 625014Ya'an, PRChina
}

\begin{abstract}
Sedum spectabile is an ornamental herbaceous perennial considered as a long-day plant. Varying levels of hormones and sugars possibly affect flower bud formation. This study aimed to determine the changes in endogenous hormones, sugars, and respiration levels in leaves and in apical buds. In addition, the current research was also conducted to observe the morphological changes during the induction, initiation and development of flower buds. Results showed that the periods of floral induction, initiation and development of $S$. spectabile were the period from $0 \mathrm{~d}$ to $1 \mathrm{~d}, 2 \mathrm{~d}$ to $10 \mathrm{~d}$ and after $11 \mathrm{~d}$ respectively under long day of 20 hours. High zeatin level in apical buds was conducive to floral induction; the increasing levels of gibberrelin and indole acetic acid favor floral initiation; floral development was regulated by mutually synergistic and antagonistic relationships of hormones. The total starch content in leaves remarkably decreased during floral induction. Moreover, soluble sugar content increased and reached the maximum level at $20 \mathrm{~d}$ of the treatment period. Afterward, soluble sugar content declined rapidly and was probably transported to the apical buds for rapid floral development. Furthermore, the total respiration of leaves maintained an upward trend; the cytochrome pathway also maintained an increasing trend after the plants were treated for $20 \mathrm{~d}$. Such changes may favour the morphological differentiation of apical buds in floral development.
\end{abstract}

Keywords: endogenous hormone, floral induction, photoperiod

\section{Introduction}

Studies on the flowering mechanism of model plants, such as Arabidopsis thaliana and rice, have shown great progress mainly by changing photoperiod, light quality, temperature, and other conditions to investigate their reactions and flowering mechanism (Song et al., 2013). After sensing changes in these conditions, plants produce many flower-related substances, which are called flowering physiological signals (Bernier et al., 1993). With many types of flowering physiological signals, plant hormones, such as cytokinin, gibberellins (GAs), auxin, etc., polyamines, oligosaccharins, zearalenone and other physiologically active substances, have been determined. Moreover, sugars, including sucrose and trehalose-6-P, have been reported as signals (Madhusudanan and Nandakumar, 1983; Komarova and Milyaeva, 1991; Lejeune et al., 1993; Roldan et al., 1999; van Dijken et al., 2004; Pau et al., 2008). These substances may be applied to induce or suppress flowering in some plants. Although $1 \%$ sucrose reportedly promotes the floral transition of late-flowering mutants, such as $c o, f c a$, and $g i$, floral transition in these mutants is delayed by further increasing sucrose concentration to 5\% (Ohto et al., 2001). Metzger (1995) presented that applied and endogenous GAs could promote floral initiation in many rosette forming long-day plants (LDPs) that would normally require a cold treatment. However, the floral initiation of some woody perennial species demands a decrease in GAs concentrations in the apical meristems (Sharp et al., 2010). Hence, these physiological signals promote or suppress flowering depending on concentration, bioactive type, and genetic background of plants.

The flower formation of some flowering plants, such as chrysanthemum (Williams et al., 1980), orchid (Lopez et al., 2003, 2005), petunia (Piringer et al., 1960), dahlia (Brøndum et al., 1993), has been successfully regulated in terms of photoperiod, light quality, and low temperature. However, the progress of studies on flowering mechanism of ornamental plants is slow probably because of the special natures (such as long 
growing cycle and complex genetic background) of them (Wang et al., 2010). Further studies on the flower formation of Sedum spectabile have not yet been reported.

S. spectabile is an ornamental plant that belongs to Crassulaceae. It is a variety of Hylotelephium spectabile. S. spectabile has been widely planted because of extensive management and high ornamental values. Furthermore, $S$. spectabile is a LD plant; hence, its flowering is limited by day length. As such, flowering in regions where day length fails to satisfy plant requirements is difficult. This study aimed to clarify changes in physiological indexes, particularly endogenous hormone levels during flower formation induced by photoperiod; this study could also provide a theoretical reference related to florescence regulation.

\section{Materials and Methods}

\section{Plant materials and treatments}

The pink cultivar of S. spectabile was introduced from Jinan (lat. $36^{\circ} \mathrm{N}$ ) to Chengdu (lat. $30^{\circ} \mathrm{N}$ ) in China and used in the current study. This plant did not flower in two years when it was subjected to natural photoperiods $\left(\right.$ lat. $\left.30^{\circ} \mathrm{N}\right)$ and short day $(\mathrm{SD})$ of $14 \mathrm{~h}$ photoperiod at $25 \pm 2^{\circ} \mathrm{C}$ and a photon flux density of 40 $\mu \mathrm{mol} \mathrm{m} \mathrm{m}^{-2} \mathrm{~s}^{-1}$; nevertheless, $S$. spectabile could flower when it was subjected to a photoperiod of $20 \mathrm{~h}(\mathrm{LD})$ at the same temperature and photon flux density. Tissue culture seedlings from the explants of non-flowering plants were grown under photoperiods of $14 \mathrm{~h}$ at $25 \pm 2{ }^{\circ} \mathrm{C}$ and a photon flux density of $40 \mu \mathrm{mol} \mathrm{m} \mathrm{m}^{-2}$. These seedlings were subjected to photoperiods of $20 \mathrm{~h}$ when eight pairs of leaves were observed. A pair of mature leaves in the fourth node from the top part and apical buds were selected to determine related physiological indexes at the end of night of $0(\mathrm{SD}), 1,3,5,10,20,30$, and $40 \mathrm{~d}$ subjected to continuous LD. To measure endogenous hormone levels, we removed plant materials from plantlets and rapidly froze them in liquid nitrogen; we then weighed and stored these materials in a refrigerator at $-80{ }^{\circ} \mathrm{C}$. To determine sugars, we initially deactivated the plant materials at $105^{\circ} \mathrm{C}$ and dried them to a constant weight at $80{ }^{\circ} \mathrm{C}$. This material was then ground in powder form, sealed, and stored in a refrigerator at $-80^{\circ} \mathrm{C}$. Fresh leaves were used to determine respiration. In addition to physiological measurements, morphological observations of the stem tip of plants were conducted. A completely randomized design was used and each treatment consisted of 15 plants.

\section{Measurement of endogenous hormones}

The levels of endogenous hormones, particularly GA, abscisic acid (ABA), zeatin (Z), and indole acetic acid (IAA), were determined using the extraction methods described by Sun et al. (2010). Frozen materials $(0.5 \mathrm{~g})$ were removed from the refrigerator $\left(-80^{\circ} \mathrm{C}\right)$ and rapidly ground into powder in liquid nitrogen. Afterward, $2 \mathrm{ml}$ of $80 \%$ methanol was added and mixed well by shaking. The materials were subjected to extraction for $4 \mathrm{~h}$ at $4{ }^{\circ} \mathrm{C}$ and centrifuged at $10,000 \times g$ for 20 $\min$ at $4^{\circ} \mathrm{C}$. The supernatant was used as hormone crude extract. One $\mathrm{ml}$ of $80 \%$ methanol was also added to the residue; the resulting mixture was subjected to extraction at $4^{\circ} \mathrm{C}$ for $2 \mathrm{~h}$ and then centrifuged at $10,000 \times g$ for $20 \mathrm{~min}$ at $4^{\circ} \mathrm{C}$. The crude extracts were combined and subsequently purified using C18 column to remove polar materials. Afterward, the purified samples were subjected to enzyme-linked immunosorbent assay.

\section{Measurement of totalstarch content}

One hundred mg of leaf powder was extracted using $80 \%$ $\mathrm{Ca}\left(\mathrm{NO}_{3}\right)_{2}$ solution to obtain a constant volume of $20 \mathrm{ml}$; afterward, $100 \mu \mathrm{l}$ of $0.01 \mathrm{~mol} \mathrm{~L}^{-1} \mathrm{I}_{2}$-KI solution was added to the resulting solution to observe colour reaction. Absorbance was then determined at $620 \mathrm{~nm}$ (Xu et al., 1998).

\section{Measurement of solublesugar}

Dry leaf powder $(100 \mathrm{mg})$ was transferred to a $15 \mathrm{ml}$ centrifuge tube. Ten $\mathrm{ml}$ of distilled water was added, and the resulting solution was placed in a water bath at $80^{\circ} \mathrm{C}$ for $30 \mathrm{~min}$. Afterward this solution was cooled and filtered; the residue was washed twice, and the supernatants were combined. Activated carbon $(10 \mathrm{mg})$ was added to decolorize the powder at $80^{\circ} \mathrm{C}$ for $20 \mathrm{~min}$; the decolorized powder was filtered and then placed in a $50 \mathrm{ml}$ volumetric flask. Total soluble sugars were analysed using anthrone reagent method described by Yemm and Willis (1954).

\section{Measurement of respiration rate}

Respiration rate was measured according to the method of Lei et al. (2010). Leaves were cut into small pieces and suspended in 20 $\mathrm{mM}$ potassium phosphate buffer ( $\mathrm{pH}$ 6.8) placed in a Clark-type oxygen electrode cuvette (Hansatech, King's Lynn, UK) at $25^{\circ} \mathrm{C}$. The inhibitors of the cytochrome pathway $(1 \mathrm{mM} \mathrm{KCN})$ and the alternative pathway (10 mM salicylhydroxamic acid, SHAM) were used. Total respiration (TR) is defined as the rate of $\mathrm{O}_{2}$ uptake of leaves without any inhibitor. Residual respiration $(\mathrm{RR})$ is defined as $\mathrm{O}_{2}$ uptake of leaves in the presence of both $\mathrm{KCN}$ and SHAM. Cytochrome pathway capacity (CPC) is defined as the difference between $\mathrm{O}_{2}$ uptake rates in the presence of SHAM and residual respiration.

\section{Statistical analysis}

Statistical analyses were performed using SPSS ver. 20 (IBM Co., USA). Duncan's multiple range test was conducted to determine significant differences at $5 \%$ levels.

\section{Results}

\section{Changes in the morphological anatomy of stem tips duringflower} formation

In the preliminary experiment, $S$. spectabile could flower when it was subjected to the photoperiod of $20 \mathrm{~h}$ for $1 \mathrm{~d}$; this result indicated that $S$. spectabile could complete floral induction during this period. Therefore, the floral induction stage covered 0 $\mathrm{d}$ to $1 \mathrm{~d}$ (stage I). The morphological characteristics changed little, except that stem tip became more flat and larger in area (Fig. 1B, arrow) at $5 \mathrm{~d}$ than $0 \mathrm{~d}$ (Fig. 1A). The inflorescence primordium was observed at $10 \mathrm{~d}$ (Fig. 1C, arrow). This period from $2 \mathrm{~d}$ to $10 \mathrm{~d}$ could be considered as floral initiation stage (stage II). The period after $11 \mathrm{~d}$ could be considered as floral development stage (stage III). Rachis and bract differentiation period occurred from $11 \mathrm{~d}$ to $30 \mathrm{~d}$ (stage IIIA). Considering that S. spectabile is a corymbose cyme with a three-branched base of inflorescence axis (Figs. 1D and 1F), we observed that inflorescence axis and the bracts on this axis had differentiated (Fig. 1D, arrow 2) or were undergoing differentiation. The primary inflorescence axis began to elongate after $30 \mathrm{~d}$, and small buds began to develop (Fig. 1G). This period from $31 \mathrm{~d}$ to $40 \mathrm{~d}$ (stage IIIB) covered primary inflorescence axis elongation and small bud differentiation periods. 
428
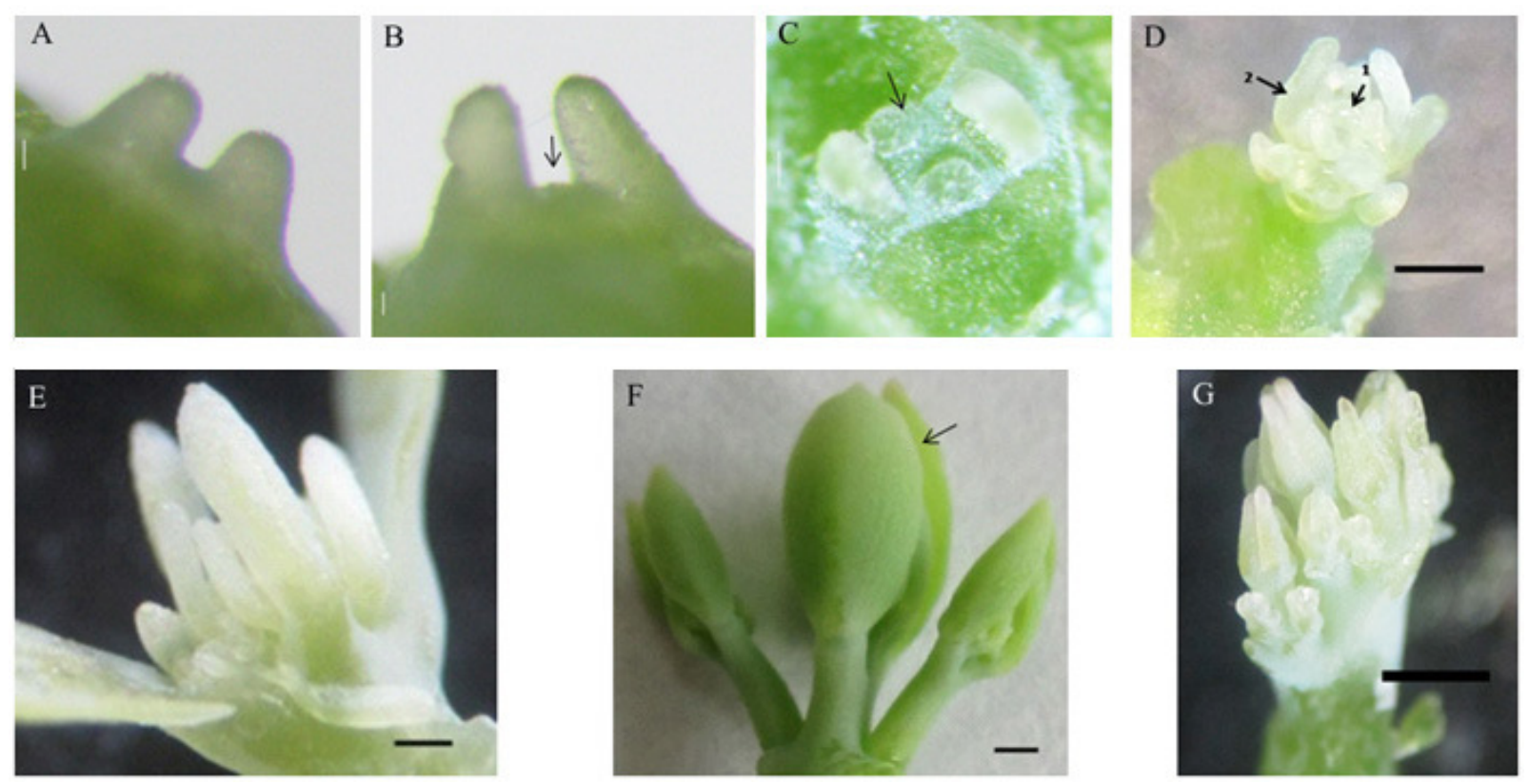

Fig. 1. Changes in the morphological anatomy of stem tips during flower formation. A, B, C, D, E, and F show the treatment of 0 , $5,10,20,30$, and $40 \mathrm{~d}$, respectively, and development of stem apex into flower bud. $\mathrm{C}$ is the state of flower bud development at 10 $\mathrm{d}$, and arrow indicates the primary primordium of inflorescence. Arrow 1 indicates the primordium of main inflorescence (i.e., inflorescence in the middle of the three branches) in the primary branch. Arrow 2 points to the bract in the base of the inflorescence branches. $\mathrm{G}$ is the inflorescence of the primary main rachis at $40 \mathrm{~d}$ (i.e., arrows in Fig. 1F). Scale bar, $0.1 \mathrm{~mm}$ (A, B, C) and $0.5 \mathrm{~mm}(\mathrm{D}, \mathrm{E}, \mathrm{F}, \mathrm{G})$.
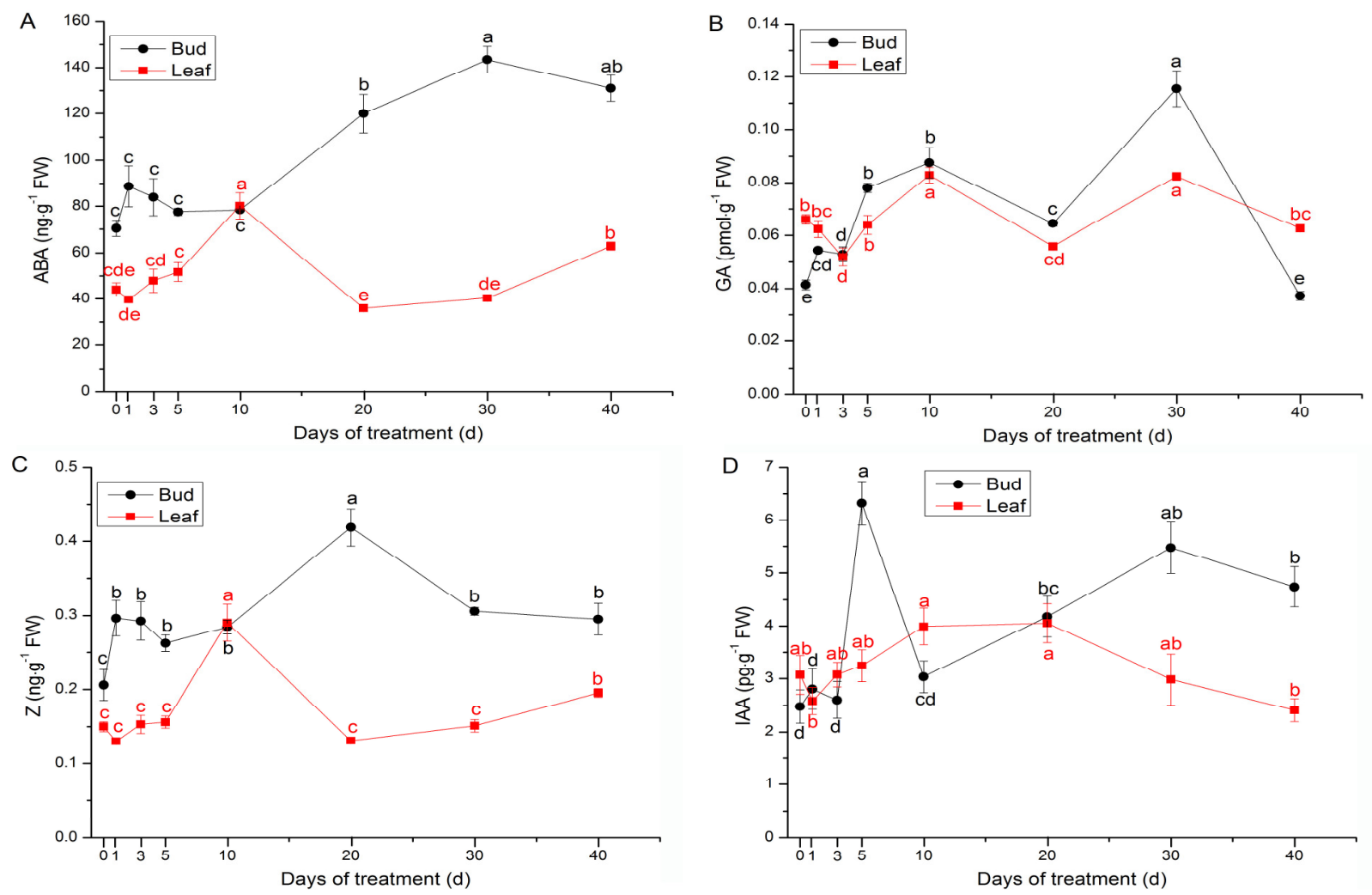

Fig. 2. Changes in the abscisic acid, gibberellin, zeatin, and indole acetic acid levels of the apical bud and leaf during flower formation. Data with the different letters are significantly different at $\mathrm{P} \leq 0.05$. 

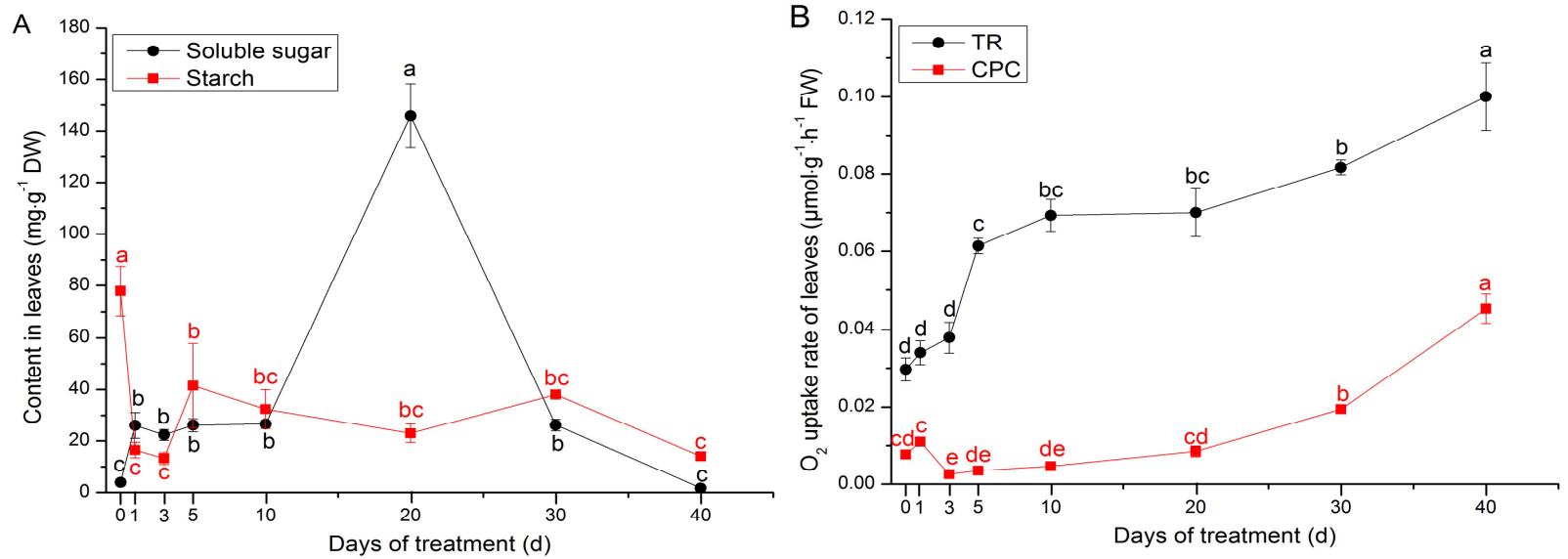

Fig. 3. Changes in sugars (A) and respiration (B) rate during flower formation. Data with the different letters are significantly different at $\mathrm{P} \leq 0.05$.

\section{Changes in hormone levels during flower formation}

Various hormonal changes during flower formation were investigated. In the buds, $\mathrm{ABA}$ concentration changed little from $0 \mathrm{~d}$ to $10 \mathrm{~d}$ and increased sharply after that and reached the peak at $30 \mathrm{~d}$ (Fig. 2A). In the leaves, $\mathrm{ABA}$ concentration increased after $5 \mathrm{~d}$ and a peak was observed at $10 \mathrm{~d} ; \mathrm{ABA}$ concentration exhibited a different change in pattern from that in the buds after $10 \mathrm{~d}$.

Significant changes of GA concentration in the buds were observed in all of the three stages during flower formation. GA concentration was significantly higher from $1 \mathrm{~d}$ to $30 \mathrm{~d}$ than at 0 $\mathrm{d}$ and two peaks were observed at $10 \mathrm{~d}$ and $30 \mathrm{~d}$ respectively (Fig. 2B). Opposite changes from $0 \mathrm{~d}$ to $3 \mathrm{~d}$ and similar changes from $3 \mathrm{~d}$ to $40 \mathrm{~d}$ were observed in the buds and the leaves (Fig. 2B). GA concentration increased and the peaks were reached at $30 \mathrm{~d}$ in the buds and leaves.

Zeatin $(\mathrm{Z})$ concentration in the buds increased significantly from $0 \mathrm{~d}$ to $1 \mathrm{~d}$, suggesting that the increase of cytokinin was important during floral induction. Afterward, $\mathrm{Z}$ concentration maintained a higher level compared to $0 \mathrm{~d}$. A significant peak at $20 \mathrm{~d}$ was observed throughout the differentiation of inflorescence primordium (stage IIIA, Fig. 2C). Likewise, Z initially was almost unchanged, then increased and subsequently decreased in the leaves. The peak was reached at $10 \mathrm{~d}$. Globally Z concentration in the buds was higher than in the leaves.

IAA concentration in the buds changed little during the first 3 days and then increased, thereby reaching the peak at $5 \mathrm{~d}$ (Fig. 2D). Afterward, IAA concentration declined rapidly; after $10 \mathrm{~d}$, IAA concentration increased and was maintained at a high level. In the leaves, IAA concentration increased slightly and then decreased steadily throughout the period.

Changes in sugars and respiration rate during flower formation Soluble sugar content in the leaves increased rapidly from $0 \mathrm{~d}$ to $1 \mathrm{~d}$ (Fig. 3A). No significant change was observed during $1 \mathrm{~d}$ to $10 \mathrm{~d}$ at higher sugar content. Soluble sugar concentration sharply increased from $10 \mathrm{~d}$ to $20 \mathrm{~d}$ and then reached the highest value. Afterward, soluble sugar concentration rapidly declined and returned to the level of SD at $0 \mathrm{~d}$. The total starch content decreased rapidly from $0 \mathrm{~d}$ to $1 \mathrm{~d}$; afterward, the total starch content increased and then decreased, but it in other periods was less than that of the control group at $0 \mathrm{~d}$.
Total respiration (TR) increased from $3 \mathrm{~d}$ and continuously increased until $40 \mathrm{~d}$ in the leaves (Fig. 3B); in particular, TR increased from $3 \mathrm{~d}$ to $5 \mathrm{~d}$, and this increase was faster in the floral initiation stage than in other periods. Cytochrome pathway capacity (CPC) changed little and remained at a low level until $20 \mathrm{~d}$. CPC increased significantly from $20 \mathrm{~d}$ to $40 \mathrm{~d}$.

\section{Discussion}

\section{Relationship between the changes in hormone levels and flower} formation

In a number of woody perennial species, a decrease in GAs concentrations in the apical meristems was required for floral initiation to occur (Sharp et al., 2010). Srikanth and Schmid (2011) concluded that GA was required for floral transition in $\mathrm{SD}$ but not in $\mathrm{LD}$. The different findings may result from the use of different experimental materials. In the present experiment, GA may be the key factor in floral development but not in floral transition. Because exogenous GA was applied on apical buds and did not induce flowering under SD treatment in our other experiment. Moreover, GA only accelerated floral development under LD. GAs are important for the development of flowers in A. thaliana (Silverstone et al., 1997). Thin sections revealed that $\mathrm{GA}_{1}$ expression was high in the inflorescence meristem, the early floral primordial and the anther. Irrespective of vernalization status, exposure to two LDs increased expression of Lolium perenne GA 20-oxidase-1 (LpGA20ox1), with endogenous GAs increasing by up to 5 -fold in shoot (MacMillan et al., 2005). The similar results were observed by Metzger and Zeevaart (1980) and Talon et al. (1991). In the morphological differentiation stage, the increasing of GA concentration may be related to internode elongation because the flower bud differentiation of $S$. spectabile is accompanied by internode elongation.

The increasing of $\mathrm{Z}$ concentration is important during floral induction. This was proved by the fact that the applied BA could induce flowering under SD treatment in our other study. During the rachis and bract differentiation period, cell division in the flower buds occurred at the fastest rate, indicating that higher concentration of $\mathrm{Z}$ was necessary to promote cell division. Similarly, cytokinin overproduction caused enlarged inflorescence and flower meristems of $A$. thaliana ( $\mathrm{Li}$ et al., 2010). Related study showed that cytokinin enhanced secondary 
430

plasmodesmata formation in shoot apical meristem (Ormenese et al., 2006), which could accelerate the exchange of substances.

In the floral initiation stage, the increasing of IAA concentration in the buds may be related to the requirement of flower bud differentiation. Samuolienè et al. (2005) reported that the increase of IAA biosynthesis during floral initiation period was observed, which induced the formation of inflorescence axis structures. The similar pattern of change in IAA was observed in this study. During the morphological differentiation period, the high level of IAA concentration may favour stem tip enlargement and internode elongation.

The increase of ABA level in the buds may be associated with the rachis and bract differentiation. This increase may be related to the transport of ABA from the leaves to the apical buds. Similarly, Koshita et al. (1999) reported that high ABA content promoted the percentage of leafless inflorescence and the number of flower buds per node of Satsuma Mandarin (Citrus unshiu Marc.).

Flower formation was not regulated by any single hormone, but mutually synergistic and antagonistic relationships of hormones to induce the formation of inflorescence structures. Auxins are typically associated with cell elongation, while auxin and cytokinin act synergistically to regulate the process of cell division (Johri and Mitra, 2001; Merkys et al., 2003). In $A$. thaliana, GA stimulation of root elongation has been shown to require auxin that affects GA production in the stem by positively regulating the expression of GA biosynthetic genes (Nemhauser et al., 2006). Cytokinin and GA act mostly in an antagonistic manner (Weiss and Ori, 2007). In the buds, IAA was the first hormone to reach the peak level $(5 \mathrm{~d})$ followed by GA $(10 \mathrm{~d})$ and $\mathrm{Z}(20 \mathrm{~d})$. In addition, IAA and GA yielded two peaks. Synergism and antagonism among Z, IAA and GA could be observed partly by the trend of the three hormones.

Relationship between the Changes in sugars and respiration rate and flower formation

In the floral induction period, the total starch content in the leaves decreased sharply, but soluble sugar content increased rapidly. This change in sugar level may be related to the requirement of floral induction and the extension of illumination period. In many other plants such as Sinapis alba and Arabidopsis thaliana (Corbesier et al., 2002), sugar content also increases during floral induction. However, whether sugar as a signal is generated in leaves and transmitted to buds remains unknown. Roldan et al. (1999) reported that total starch metabolism and a transient increased in sugar levels in the leaves were related to the output of the shoot apical meristem. The dark morphogenesis and flowering of $A$. thaliana was promoted by sucrose. The delay flowering phenotype of several mutants were saved by the addition of $1 \%$ sucrose. But sugar may affect floral transition depending on the concentration of sugars, the genetic background of the plants and when the sugar was introduced (Ohto et al., 2001). Moreover, trehalose-6-P has been considered as a flowering signal (Paul et al., 2008). Carbohydrates may not have a direct effect to induce floral initiation (Ulger et al., 2004). Further studies should be conducted to reveal the active mechanism of sugar in floral transition. It is certain that the increase in soluble sugar can provide more substrates for respiration.

Considering the changes in respiration, TR of the leaves increased rapidly in the floral initiation stage, indicating that more ATP was probably produced to be used to transport sugars and signals to the buds. TR increased from $20 \mathrm{~d}$ to $40 \mathrm{~d}$ in agreement with the result of the decrease in soluble sugar content. However, CPC remained at a low level at first, indicating that other respiration pathways, such as alternative pathways, accounted for a large proportion in the leaves.

\section{Conclusions}

The floral induction, initiation and development of $S$. spectabile were the period from $0 \mathrm{~d}$ to $1 \mathrm{~d}, 2 \mathrm{~d}$ to $10 \mathrm{~d}$ and after 11 $\mathrm{d}$ respectively under long day of $20 \mathrm{~h}$. High $\mathrm{Z}$ level in apical buds was conducive to floral induction; the increasing levels of GA and IAA favour flower initiation. The changes of sugars and the increasing of respiration also play important roles during flower formation.

\section{Acknowledgments}

This study was supported by the Doctoral Foundation of the Ministry of Education (20110181110059, 20120181130008), National Natural Science Foundation of China (31171835, 31270290, J1103518, 31371555), Sichuan and Chengdu Science and Technology Foundation (2010JQ0080, 11DXYB097JH027,2012JY0078).

\section{References}

Bernier G, Havelange A, Houssa C, Petitjean A, Lejeune P (1993). Physiological signals that induce flowering. The Plant Cell 5(10):11471155.

Brøndum JJ, Heins RD (1993). Modeling temperature and photoperiod effects on growth and development of Dablia. Journal of the American Society for Horticultural Science 118(1):36-42.

Corbesier L, Bernier G, Périlleux C (2002). C:N ratio increases in the phloem sap during floral transition of the long-day plants Sinapis alba and Arabidopsis thaliana. Plant and Cell Physiology 43(6):684-688.

Komarova EN, Milyaeva EL (1991). Changes in content and distribution of starch in stem apices of bicolored coneflower during the period of flowering evocation. Soviet Plant Physiology 38(1):46-51.

Koshita Y, Takahara T, Ogata T, Goto A (1999). Involvement of endogenous plant hormones (IAA, ABA, GAs) in leaves and flower bud formation of satsuma mandarin (Citrus unshiu Marc.). Scientia Horticulturae 79(3):185-194.

Lei T, Feng H, Sun X, Dai QL, Zhang FH, Liang G, Lin HH (2010). The alternative pathway in cucumber seedlings under low temperature stress was enhanced by salicylic acid. Plant Growth Regulation 60(1):35-42.

Lejeune P, Bernier G, Requier MC, Kinet JM (1993). Sucrose increase during floral induction in the phloem sap collected at the apical part of the shoot of the long-day plant Sinapis alba L. Planta 190(1):71-74.

Li XG, Su YH, Zhao XY, Li W, Gao XQ, Zhang XS (2010). Cytokinin overproduction-caused alteration of flower development is partially mediated by CUC2 and CUC3 in Arabidopsis. Gene 450(1):109-120.

Lopez RG, Runkle ES, Heins RD (2005). Flowering of the orchid Miltoniopsis Augres 'Trinity' is influenced by photoperiod and temperature. Acta Horticulturae 683:175-178. 
Lopez RG, Runkle ES, Heins RD, Whitman CM (2003). Temperature and photoperiodic effects on growth and flowering of Zygopetalum Redvale 'Fire Kiss' Orchids. Acta Horticulturae 624:155-159.

MacMillan CP, Blundell CA, King RW (2005). Flowering of the grass Lolium perenne. effects of vernalization and long days on gibberellin biosynthesis and signaling. Plant Physiology 138(3):1794-1806.

Madhusudanan KN, Nandakumar S (1983). Carbohydrate changes in shoot tip and subtending leaves during ontogenetic development of pineapple. Zeitschrift für Pflanzenphysiologie 110(5):429-438.

Metzger JD (1995). Hormones and reproductive development. In: Davies PJ (Ed). Plant Hormones. Kluwer Academic Press, Dordrecht, The Netherlands pp 617-648.

Metzger JD, Zeevaart JAD (1980). Effect of photoperiod on the levels of endogenous gibberellins in spinach as measured by combined gas chromatography-selected ion current monitoring. Plant Physiology 66(5):844-846.

Nemhauser JL, Hong FX, Chory J (2006). Different plant hormones regulate similar processes through largely nonoverlapping transcriptional responses. Cell 126(3):467475 .

Ohto M, Onai K, Furukawa Y, Aoki E, Araki T, Nakamura K (2001). Effects of sugar on vegetative development and floral transition in Arabidopsis. Plant Physiology 127(1):252-61.

Ormenese S, Bernier G, Périlleux C (2006). Cytokinin application to the shoot apical meristem of Sinapis alba enhances secondary plasmodesmata formation. Planta 224(6):14811484.

Paul MJ, Primavesi LF, Jhurreea D, Zhang YH (2008). Trehalose metabolism and signaling. Annual Review of Plant Biology 59:417-441.

Piringer AA, Cathey HM (1960). Effect of photoperiod, kind of supplemental light and temperature on the growth and flowering of petunia plants. Proceedings American Society for Horticultural Science 76:649-660.

Roldan M, Gomez-Mena C, Ruiz-Garcia L, Salinas J, MartinezZapater JM (1999). Sucrose availability on the aerial part of the plant promotes morphogenesis and flowering of Arabidopsis in the dark. Plant Journal 20(5):581-590.

Sharp RG, Else MA, Davies WJ, Cameron RW (2010). Gibberellin-mediated suppression of floral initiation in the long-day plant Rhododendron cv. Hatsugiri. Scientia Horticulturae 124(2):231-238.
Silverstone AL, Chang CW, Krol E, Sun TP (1997). Developmental regulation of the gibberellin biosynthetic gene GA1 in Arabidopsis thaliana. Plant Journal 12(1):9-19.

Song YH, Ito S, Imaizumi T (2013). Flowering time regulation: photoperiod- and temperature-sensing in leaves. Trends in Plant Science 18(10):575-583.

Srikanth A, Schmid M (2011). Regulation of flowering time: all roads lead to Rome. Cellular \& Molecular Life Sciences 68(12):2013-2037.

Sun LA, Zhang M, Ren J, Qi JX, Zhang GJ, Leng P (2010). Reciprocity between abscisic acid and ethylene at the onset of berry ripening and after harvest. BMC Plant Biology 10(1):257.

Talon M, Zeevaart JAD (1992). Stem elongation and changes in the levels of gibberellins in shoot tips induced by differential photoperiodic treatments in the long-day plant Silene armeria. Planta 188(4):457-461.

Ulger S, Sonmez S, Karkacier M, Ertoy N, Akdesir O, Aksu M (2004). Determination of endogenous hormones, sugars and mineral nutrition levels during the induction, initiation and differentiation stage and their effects on flower formation in olive. Plant Growth Regulation 42(1):89-95.

van Dijken AJ, Schluepmann H, Smeekens SC (2004). Arabidopsis trehalose-6-phosphate synthase 1 is essential for normal vegetative growth and transition to flowering. Plant Physiology 135(2):969-977.

Wang Y, Ma YP, Dai SL (2010). The molecular mechanism in regulation of flowering in ornamental plants. Chinese Bulletin of Botany 45(6):641-653.

Weiss D, Ori N (2007). Mechanisms of cross talk between gibberellin and other hormones. Plant Physiology 144(3):1240-1246.

Williams JD, Groves RH (1980). The influence of temperature and photoperiod on growth and development of Parthenium hysterophorus L. Weed Research 20(1):47-52.

Xu CJ, Chen WJ, Chen KS, Zhang SL (1997). A simple method for determining the content of starch-iodine colorimety. Biotechnology 8(2):41-43.

Yemm EW, Willis AJ (1954). The estimation of carbohydrates in plant extracts by anthrone. Biochemical Journal 57(3):508514. 